\title{
Meningioma cells express primary cilia but do not transduce ciliary Hedgehog signals
}

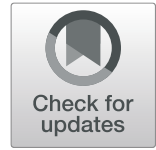

\author{
Sarah Findakly ${ }^{1,2}$, Abrar Choudhury ${ }^{1,2}$, Vikas Daggubati ${ }^{1,2}$, Melike Pekmezci ${ }^{3}$, Ursula E. Lang ${ }^{3,4}$ and \\ David R. Raleigh ${ }^{1,2^{*}}$
}

\begin{abstract}
Meningiomas are the most common primary intracranial tumors, but treatment options for meningioma patients are limited due to incomplete understanding of tumor biology. A small percentage of meningiomas harbor somatic variants in the Hedgehog pathway, a conserved gene expression program that is essential for development and adult stem cell homeostasis. Hedgehog signals are transduced through primary cilia, and misactivation of the Hedgehog pathway is known to underlie cancer. Nevertheless, the mechanisms of Hedgehog signaling in meningioma are unknown. Here, we investigate mechanisms of ciliary Hedgehog signaling in meningioma using tissue microarrays containing 154 human meningioma samples, NanoString transcriptional profiling, primary meningioma cells, pharmacology, and CRISPR interference. Our results reveal that meningiomas of all grades can express primary cilia, but that cilia are less prevalent among anaplastic tumors. Moreover, we find that expression of Smoothened alleles that are oncogenic in other contexts fail to activate the Hedgehog transcriptional program or promote proliferation in primary meningioma cells. These data reveal that meningiomas can express the subcellular structure necessary for canonical Hedgehog signaling, but suggest that they do not transduce ciliary Hedgehog signals.
\end{abstract}

Keywords: Cilia, Hedgehog, Meningioma, Primary cilium, Smoothened, Vismodegib

\section{Introduction}

Meningiomas arising from the lining of the central nervous system are the most common primary intracranial tumors [15]. The World Health Organization (WHO) classifies meningiomas according to mitotic activity and histopathologic features associated with aggressive clinical behavior [13]. WHO grade I meningiomas have low mitotic activity and can be effectively treated with surgery and radiation [3]. In contrast, high grade meningiomas, which account for $20-30 \%$ of cases, are a significant cause of neurologic morbidity and mortality [3]. Thus, there is an urgent, unmet need for new meningioma treatments. However, new therapies for meningioma patients have

\footnotetext{
* Correspondence: david.raleigh@ucsf.edu

'Department of Radiation Oncology, University of California San Francisco, San Francisco, CA, USA

${ }^{2}$ Department of Neurological Surgery, University of California San Francisco, San Francisco, CA, USA

Full list of author information is available at the end of the article
}

been encumbered by limited understanding of meningioma biology, and a lack of druggable mechanisms underlying meningioma growth [3].

A very small percentage of meningiomas harbor somatic variants in the Hedgehog pathway [2, 4, 5, 22], a conserved gene expression program that is essential for development and adult stem cell homeostasis [9]. Misactivation of the Hedgehog pathway can cause cancer, including basal cell carcinoma, the most common cancer in the United States, and medulloblastoma, the most common malignant brain tumor in children [18]. Meningiomas express Hedgehog genes [12], and the majority of Hedgehog pathway variants in meningiomas are mutually exclusive from NF2 variants. However, Hedgehog pathway mutations are found in low grade meningiomas with favorable outcomes after treatment with standard therapies [19]. Moreover, overexpression of an oncogenic allele of the Hedgehog pathway activator Smoothened (SMO) promotes arachnoid 
hyperproliferation in mice, but does not cause meningiomas of the same size or number as inactivating alleles of $N f 2$ [1]. These data suggest that the mechanisms of Hedgehog signaling in meningiomas remain incompletely understood.

Vertebrate Hedgehog signals are transduced through the primary cilium, an antennae that projects from the surface of most cells [7]. Hedgehog ligand binding to Patched (PTCH) allows SMO to accumulate in cilia and activate the GLI family of transcription factors, which translocate to the nucleus and activate the Hedgehog transcriptional program [9]. Primary cilia are necessary for canonical Hedgehog signal transduction, but are not sufficient to activate the Hedgehog transcriptional program, which is controlled by mechanisms downstream of cilia. A clinical trial exploring the efficacy of the SMO inhibitor vismodegib in meningioma was initiated (NCT02523014), but vismodegib inhibits ciliary SMO, and it is unknown if meningiomas express primary cilia or encode the Hedgehog transcriptional program.

\section{Methods}

\section{Cell culture and small molecule treatments}

The primary human meningioma M10G cell line was derived from a fresh meningioma resection (WHO grade I, NF2 wild type, Chr22q loss of 1 copy, convexity) by mechanically mincing approximately $100 \mathrm{mg}$ of tumor tissue in Hanks' Balanced Salt Solution (HBSS) and then plating in media with a 1:1 ratio of Dulbecco's Modified Eagle Medium (DMEM) and F12 (Life Technologies, \#10565) and Neurobasal medium (Life Technologies, \#21103), supplemented with $5 \%$ fetal bovine serum (FBS) (Life Technologies, \#16141), B-27 supplement without vitamin A (Life Technologies, \#12587), N-2 supplement (Life Technologies, \#17502), 1X GlutaMAX (Life Technologies, \#35050), 1 mM NEAA (Life Technologies, \#11140), $100 \mathrm{U} / \mathrm{mL}$ Anti-Anti (Life Technologies, \#15240), 20 ng/mL EGF (R\&D systems, Minneapolis, MN, \#236-EG), and 20 ng/mL FGF2 (Peprotech, Rocky Hill, NJ, \#100-18C).

The primary human meningioma BenMen cell line (WHO grade I, NF2-mutant, falx) was originally derived from a meningothelial meningioma and transfected with hTERT to achieve immortalization [17]. Cells were cultured in DMEM (10313021, Life Technologies) supplemented with 10\% FBS and 1X GlutaMAX, which was also used to culture NIH3T3 (CRL-1658, ATCC) and HEK293T (CRL-3216, ATCC) cells.

For ciliation and Hedgehog signaling assays, NIH3T3, BenMen and M10G cultures were transitioned to OptiMEM (31985062, Thermo Fisher Scientific) and treated with recombinant Sonic Hedgehog $1 \mu \mathrm{g} / \mathrm{ml}$ (1845, R\&D Systems), Smoothened agonist 100 nM (566660, Calbiochem) or vehicle control, for $24 \mathrm{~h}$.

\section{Cell transfection}

$S M O$, the oncogenic allele $S M O^{W 535 L}$, and the somatic variant $S M O^{L 412 F}$ were cloned into the pEGFP vector, and constitutively active GLI2 (GLI2 ${ }^{\text {CLEG }}$ ) was cloned into pCMV vector. According to the manufacturer's instructions, Fugene HD reagent (Promega, E2311) was used for transfection of constructs into NIH3T3, BenMen and M10G cells. Cells were harvested for experimentation $72 \mathrm{~h}$ after transfection.

\section{CRISPR interference}

Lentiviral particles containing pMH0001 (UCOE-SFFVdCas9-BFP-KRAB, Addgene \#85969) were produced by transfecting HEK293T cells with standard packaging vectors using the TransIT-Lenti Transfection Reagent (Mirus Bio, MIR 6605). M10G cells were stably transduced with lentiviral particles to generate ${\mathrm{M} 10 \mathrm{G}^{\mathrm{dCa}-}}^{-}$ s9-KRAB cells by isolating BFP-expressing cells using fluorescence activated cell sorting on a Sony SH800.

Single-guide RNA (sgRNA) protospacer sequences were individually cloned into the pCRISPRia-v2 vector (Addgene plasmid \#84832), between the BstXI and BlpI sites, by ligation. Each vector was verified by Sanger sequencing of the protospacer. One sgRNA expression vector with the following protospacer was cloned for non-targeting control sgRNAs (ncRNA) (5'-GCTGCA TGGGGCGCGAATCA-3'), PTCH1 sgRNAs (sgPTCH1) (5'-AAATGTACGAGCACTTCAAG-3') and SMO sgRNAs (sgSMO) (5'-CAAGAACTACCGATACCGTG$\left.3^{\prime}\right)$. Lentivirus was generated as described above for each sgRNA expression vector, and $\mathrm{M} 10 \mathrm{G}^{\mathrm{dCas9}-\mathrm{KRAB}}$ cells were independently transduced with lentivirus from each sgRNA expression vector, then selected to purity using $20 \mu \mathrm{g} / \mathrm{mL}$ puromycin over 7 days.

\section{Meningiomas}

Meningioma tissue microarrays were comprised of cases treated with surgery at the University of California San Francisco (UCSF) between 2003 to 2012. Demographic and clinical data were obtained from the medical record. For all cases, diagnostic imaging was re-reviewed to confirm the extent of resection and determine the occurrence and timing of local recurrence, which was defined as local recurrence of any size after gross-total resection, or growth of $\geq 20 \%$ along any dimension after subtotal resection. Mortality data and cause of death were extracted from the electronic medical record, institutional cancer registry, Surveillance, Epidemiology, and End Results (SEER), Department of Motor Vehicles (DMV), Social Security, and nationwide hospital databases, and publicly available obituaries. Overall survival was defined as the length of time from resection of meningioma to death. This study was approved by the Institutional 
Review Board, Human Research Protection Program Committee on Human Research, protocol 18-24,633.

\section{Meningioma and meningioma tissue microarray ciliary immunofluorescence}

Meningioma tissue microarrays were created as previously described [14]. In brief, two $2 \mathrm{~mm}$ cores were taken from each meningioma block, along with control tissue from normal adult brain, normal adult meninges, 2 lung adenocarcinomas, and placenta. All meningioma diagnoses and grades were re-reviewed according to current diagnostic criteria by a board-certified neuropathologist (MP) [13]. Only patients with demographic, histopathologic, radiologic, and comprehensive clinical follow-up data who consented to tumor sampling for research were included. Ciliary immunofluorescence was performed as previously described [11]. In brief, sections were deparaffinized in xylene, rehydrated through graded ethanol dilutions and subjected to antigen retrieval using CC1 TRIS buffer (Ventana Medical Systems); labeled with primary antibodies including Pericentrin (PA5-54109, Thermo Fisher Scientific) and $\gamma$ Tubulin (T5192, Sigma) to mark centrosomes, and acetylated tubulin to mark cilia (T6793, Sigma). Alexa Fluor secondary antibodies and DAPI $(62,248$, Thermo Fisher Scientific) were used, and sections were mounted in mounted in ProLong Diamond Antifade Mountant (Thermo Fisher Scientific).

\section{Microscopy}

Fluorescence microscopy was performed on a Zeiss LSM 800 confocal laser scanning microscope with a PlanApo $20 \mathrm{X}$ air objective. Images were processed and quantified from a representative region of each tumor using ImageJ. Cilia prevalence was quantified as the ratio of cilia to nuclei. Cilia length was quantified using a region of interest calculation.

\section{NanoString transcriptional profiling}

NanoString transcriptional profiling from formal-fixed paraffin-embedded meningiomas was performed as previously described [21]. In brief, total RNA was extracted from tumor cores containing $75 \%$ or more tumor cells, as determined by hematoxylin and eosin (H\&E) staining. The GX Human Cancer Reference NanoString panel codeset, containing 30 additional meningioma related genes, were synthesized by NanoString Technologies. Of note, SMO was the only Hedgehog pathway gene included in this panel. RNA (200 ng per meningioma) was analyzed by the NanoString nCounter Analysis System at NanoString Technologies, according to the manufacturer's protocol. Data were preprocessed, normalized against a panel of housekeeping genes, and $\log 2$ - transformed count data were centered and scaled within-meningiomas using a Z-score transformation.

\section{Primary meningioma cell immunofluorescence}

Immunofluorescence for acetylated tubulin (AcTub) and Ki67 from meningioma cells was performed on glass coverslips. Cells were fixed in $4 \%$ paraformaldehyde, blocked in 2.5\% BSA (Sigma) and 0.1\% Triton X-100 (Sigma) in Phosphate Buffered Saline (PBS) for $30 \mathrm{~min}$ at room temperature (Thermo Fisher Scientific), and labeled with anti-Ki67 (ab15580, Abcam), antiSmoothened (20787-1-AP, ProteinTech), anti-Centriolin (sc-365,521, Santa Cruz), anti-Arl13b (17711-1-AP, ProteinTech) or anti-acetylated tubulin (T6793, Sigma) primary antibodies at room temperature for $3 \mathrm{~h}$. Cells were labeled with Alexa Fluor secondary antibodies and DAPI to mark DNA (Life Technologies, H3570) for $1 \mathrm{~h}$ at room temperature, and were mounted in ProLong Diamond Antifade Mountant (Thermo Fisher Scientific).

\section{Quantitative reverse transcriptase polymerase chain reaction}

RNA was isolated from cells using the RNEasy Mini Kit and a QiaCube (QIAGEN), and cDNA was synthesized using the iScript cDNA Synthesis Kit (Bio-Rad) and a ProFlex thermocycler (Thermo Fisher Scientific). Target genes were amplified using PowerUp SYBR Green Master Mix and a QuantStudio 6 thermocycler (Thermo Fisher Scientific). Gene expression was calculated using the $\triangle \triangle \mathrm{Ct}$ method, with normalization to human GAPDH (sense: 5' -CTTCACCACCATGGAGAAGGC-3', antisense: 5'-GGCATGGACTGTGGTCATGAG-3') or mouse Gapdh (sense: 5' -TGCCCCCATGTTTGTGATG3', antisense: 5' - TGTGGTCATGAGCCCTTCC-3'). Target human gene primers were PTCH1 (sense: $5^{\prime}$-GAAGAAGGTGCTAATGTCCTGAC - 3', antisense: $5^{\prime}$ GTCCCAGACTGTAATTTCGCC -3'), SMO (5' -GAAG TGCCCTTGGTTCGGA - 3', antisense: $5^{\prime}$-GCAGGGTA GCGATTCGAGTT - 3') and GLI1 (sense 5'-AGCCTT CAGCAATGCCAGTGAC-3', antisense: 5' - GTCAGG ACCATGCACTGTCTTG-3'). Target mouse gene primers were Gli1 (sense 5'- GGTGCTGCCTATAG CCAGTGTCCTC-3', antisense: 5'-GTGCCAATCC GGTGGAGTCAGACCC - 3').

\section{Statistics}

All experiments were performed with at least 3 biologic replicates and at least 3 technical replicates. Lines represent mean and error bars represent standard error of the mean. Local recurrence free and overall survival were estimated using the Kaplan-Meier method and compared by log-rank tests. ANOVA and two-tailed Student's unpaired t-test were used to compare groups, and in all 
cases, statistical significance, as denoted by (*), was defined as $p \leq 0.05$.

\section{Results and discussion}

To investigate mechanisms of Hedgehog signaling in meningioma, we created tissue microarrays comprised of 154 meningiomas from patients with comprehensive clinical follow-up data (median follow-up 4.3 years) who were treated with standard therapies at a single institution from 2003 to 2012 [14]. Tissue microarray tumors were re-reviewed according to current diagnostic criteria [13], revealing 113 WHO grade I (73\%), 30 grade II (20\%, atypical) and 11 grade III (7\%, anaplastic) meningiomas in 105 women (68\%) and 49 men (32\%), as described in Supplementary Table S1. Using these microarrays, we performed immunofluorescence and confocal microscopy and discovered that meningiomas of all grades express primary cilia (Fig. 1a), but that cilia were less common in anaplastic meningiomas (Fig. 1b). Consequently, local freedom from recurrence was worse for meningiomas lacking primary cilia (Fig. 1c, Supplementary Table S1), a correlative observation likely attributable to meningioma grade that may not indicate a causative role for loss of cilia in meningioma tumorigenesis. To determine if cilia prevalence correlated with Hedgehog gene expression in meningiomas, we performed NanoString transcriptional profiling for $S M O$ from 26 tumors, which failed to identify any associations between $S M O$ expression and cilia prevalence in meningioma (Fig. 1d). Further, we identified no differences in overall survival according to ciliary length or prevalence; no differences in ciliary length or SMO expression according to meningioma grade; no differences in $S M O$ expression according to ciliary length; no differences in local freedom from recurrence according to ciliary length or SMO expression; no differences in ciliary length or prevalence according to patient sex, prior treatment, or meningioma location; and no associations between ciliary length or prevalence and meningioma size or MIB1 labeling index (Supplementary Table S1). Thus, meningiomas can express the structure necessary for canonical Hedgehog signal transduction, but are less likely to do so when anaplastic (WHO grade III). In conjunction with the observation that Hedgehog pathway somatic variants are enriched in low grade meningiomas with favorable outcomes after treatment with standard therapies [19], our findings suggest that Hedgehog signaling does not underlie meningioma progression. In further support of this hypothesis, we show that cilia expression in meningioma does not correlate with expression of SMO in vivo. However, our data are limited by the fact that the genomic status of the meningiomas included in our tissue microarrays is unknown, and may not have included tumors with Hedgehog pathway variants, which are very rare in human meningiomas [19]. To shed light on this possible explanation, we identified 3 meningiomas harboring inactivating variants in SUFU, a negative regulator of the Hedgehog pathway, using clinical targeted next-generation sequencing [10]. Consistent with our hypothesis that ciliary expression does not correlate with Hedgehog signal transduction in meningioma, immunofluorescence and confocal microscopy revealed that all 3 meningiomas with loss of SUFU failed to express primary cilia (Supplementary Fig. S1). Of note, we have identified no meningiomas harboring $S M O$ variants at our institution to date using either clinical targeted nextgeneration sequencing, or exploratory whole exome sequencing [20].

To further interrogate Hedgehog signaling mechanisms in meningioma cells, we performed immunofluorescence and confocal microscopy for cilia in BenMen and M10G primary human meningioma cells, both of which were derived from WHO grade I tumors. We
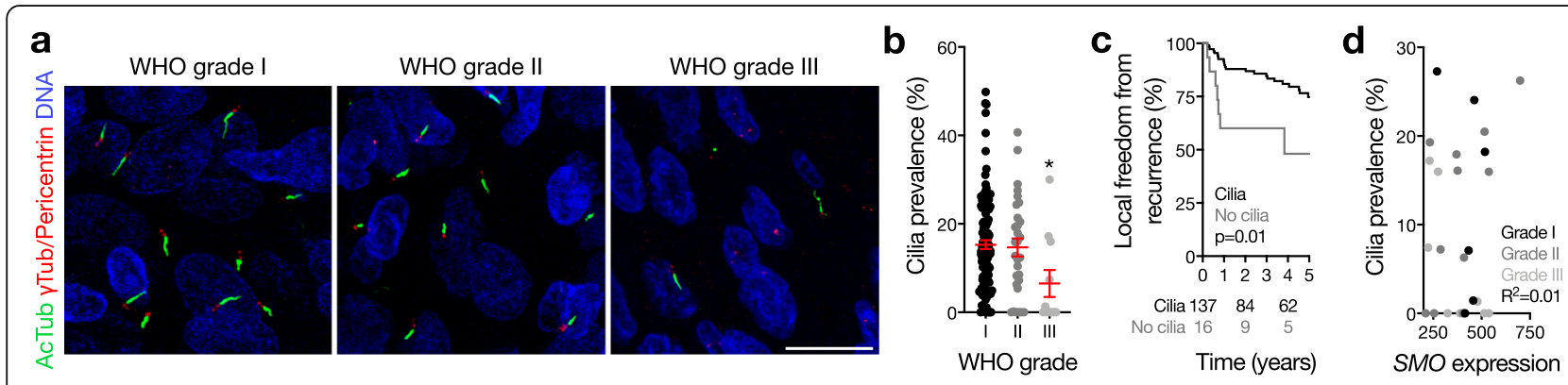

Fig. 1 Meningiomas express primary cilia. a Confocal immunofluorescence microscopy for the ciliary marker acetylated tubulin (AcTub), the ciliary base/centriole markers gamma tubulin (YTub) and pericentrin, and DNA (DAPI) reveals that meningiomas express primary cilia. b Quantitative confocal immunofluorescence microscopy shows that WHO grade III meningiomas express less cilia than other meningiomas $\left(^{*} p=0.04\right.$ ANOVA, $p=0.01$ Student's $t$ test). $\mathbf{c}$ Consistent with loss of cilia in high grade meningiomas, local freedom from recurrence is shorter in meningiomas without primary cilia compared to meningiomas expressing primary cilia (log-rank test). $\mathbf{d}$ Nanostring transcriptional profiling demonstrates that SMO expression does not correlate with cilia prevalence in meningioma 
found that M10G cells expressed primary cilia, but BenMen cells did not (Fig. 2a, b). To determine if meningioma cells encode the Hedgehog transcriptional program, we expressed ciliary and post-ciliary activators of the Hedgehog pathway in primary meningioma cells, and assessed Smoothened accumulation in meningioma cilia, and quantified output of the Hedgehog transcriptional program. In parallel, we transfected BenMen and M10G meningioma cells with (i) wild type SMO; (ii) an oncogenic allele of SMO identified in BCC and medulloblastoma $\left(\mathrm{SMO}^{\mathrm{W} 535 \mathrm{~L}}\right)$ [18]; (iii) the most common SMO somatic variant identified in meningioma $\left(\mathrm{SMO}^{\mathrm{L} 412 \mathrm{~F}}\right)[2$, $4,5,22]$, which is unresponsive to vismodegib in other cancers [20]; (iv) a constitutively active allele of GLI2

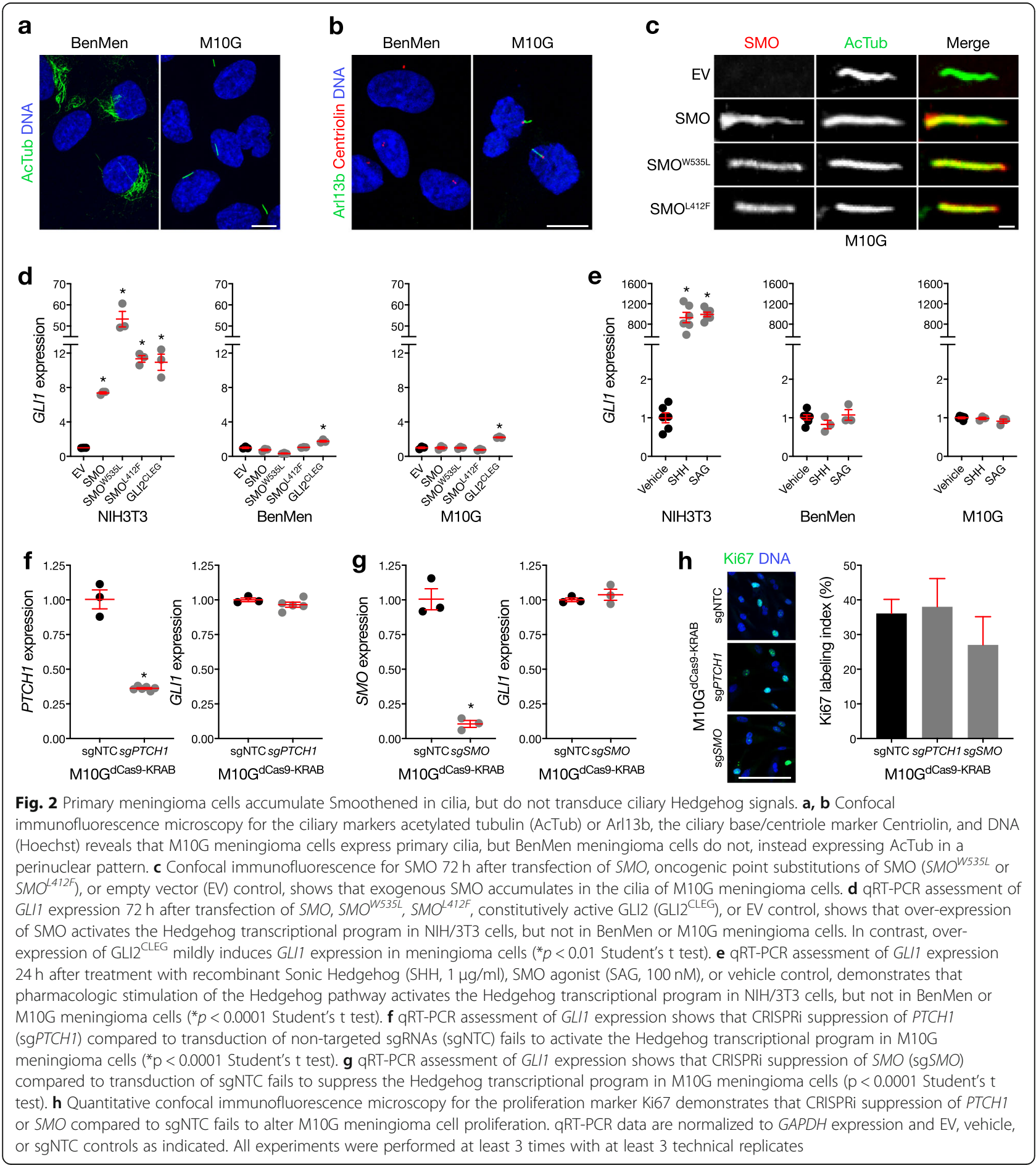


(GLI2 ${ }^{\mathrm{CLEG}}$ ), the primary activator of the Hedgehog transcriptional program downstream of cilia; or (v) empty vector (EV) control. We found that SMO, SMO ${ }^{\text {W535L }}$ and $\mathrm{SMO}^{\mathrm{L} 412 \mathrm{~F}}$ all accumulated in cilia of M10G meningioma cells (Fig. 2c). However, when we assessed the Hedgehog transcriptional program in these cells using quantitative reverse transcriptase polymerase chain reaction (qRT-PCR) for the Hedgehog target gene GLI1, we found that over-expression of SMO, SMO ${ }^{\mathrm{W} 535 \mathrm{~L}}$ and $\mathrm{SMO}^{\mathrm{L} 412 \mathrm{~F}}$ failed to activate the Hedgehog transcriptional program in meningioma cells (Fig. 2d). In contrast, ciliated NIH3T3 cells, which encode the Hedgehog transcriptional program, dramatically induced GLII expression in response to $\mathrm{SMO}, \mathrm{SMO}^{\mathrm{W} 535 \mathrm{~L}}, \mathrm{SMO}^{\mathrm{L} 412 \mathrm{~F}}$ and GLI2 ${ }^{\text {CLEG }}$ (Fig. 2d). Consistently, pharmacologic stimulation of the Hedgehog pathway induced GLI1 expression from NIH3T3 cells, but not from meningioma cells (Fig. 2e). GLI2 ${ }^{\text {CLEG }}$ mildly induced GLI1 expression in meningioma cells (Fig. 2d), suggesting that somatic variants targeting the Hedgehog pathway downstream of cilia may activate Hedgehog signaling in meningioma. Nevertheless, there are currently no clinically tractable inhibitors of GLI transcription factors that could be used to treat meningioma patients.

To validate our finding that primary meningioma cells do not transduce ciliary Hedgehog signals, we generated ciliated M10G cells stably expressing the CRISPR interference (CRISPRi) components dCas9-KRAB [8], and stably suppressed $P T C H 1$ or $S M O$ by transducing single guide RNAs (sgRNAs). qRT-PCR revealed that PTCH1 suppression failed to activate the Hedgehog transcriptional program (Fig. 2f), and SMO suppression failed to inhibit the Hedgehog transcriptional program (Fig. 2g), compared to transduction of non-targeted sgRNA controls (sgNTC) in M10G ${ }^{\mathrm{dCas} 9-\mathrm{KRAB}}$ cells. Moreover, immunofluorescence and quantitative confocal microscopy for the proliferation marker Ki67 demonstrated that neither $\operatorname{sg} P T C H 1$ nor $\operatorname{sgSMO}$ altered the proliferation of M10G $^{\text {dCas9-KRAB }}$ cells (Fig. 2h).

\section{Conclusions}

In summary, our results reveal that meningiomas express primary cilia, but do not transduce ciliary Hedgehog signals. These data are consistent with larger studies of meningioma transcriptomics using RNA sequencing, which fail to identify aberrations in the Hedgehog pathway in these tumors $[16,20]$. Thus, in the context of negative trials of Hedgehog pathway inhibitors for other cancers where the mechanisms of Hedgehog signaling were not fully understood [6], the data presented here suggest that further preclinical translation research is necessary before new clinical studies of Hedgehog pathway inhibitors are opened for meningioma patients.

\section{Supplementary information}

Supplementary information accompanies this paper at https://doi.org/10. 1186/s40478-020-00994-7.

Additional file 1: Supplementary Fig. S1. Meningiomas harboring inactivating variants in SUFU, a negative regulator of the Hedgehog pathway, do not express primary cilia. Confocal immunofluorescence microscopy for the ciliary marker acetylated tubulin (AcTub), the ciliary base/centriole markers Pericentrin and $\gamma$ Tubulin ( $\gamma$ Tub), and DNA (DAPI) reveals that meningiomas harboring in activating variants in SUFU do not express primary cilia. Of note, 2 of 3 meningiomas harboring inactivating variants in SUFU also harbored inactivating variants in NF2.

Additional file 2: Supplementary Table S1. Meningioma characteristics. For binary variables such as skull base location, recurrent presentation, prior surgery, prior radiotherapy, GTR, local failure, and death, 1 denotes an event and 0 denotes the absence of an event. Male sex is denoted as 1 , and female sex is denoted as 0 . Radiotherapy target delineation software (MIM, Cleveland, $\mathrm{OH}$ ) was used to contour and calculate meningioma volumes. Time to failure and survival time is shown in years. Ciliary length is shown in micrometers.

\section{Abbreviations}

GLI: Glioma associated oncogene; GTR: Gross total resection; LI: Labeling index; MIB1: Mindbomb E3 Ubiquitin Protein Ligase 1; NIH3T3: National Institutes of Health mouse fibroblast 3T3 cells; OTHR: Other; PD: Progressive disease; PTCH: Patched; RT: Radiotherapy; SMO: Smoothened; TX: Treatment; UNKN: Unknown

\section{Acknowledgements}

Not applicable.

\section{Authors' contributions}

SF performed experiments and formal analysis of data. AC analyzed and interpreted patient level data regarding NanoString transcriptional profiling. VD performed experiments relating to Hedgehog transcriptional program output in vitro. MP and UL performed sectioning and immunohistochemistry of human meningioma samples. DRR conceptualized the study, wrote the manuscript, and provided project administration, resources, and supervision. All authors read and approved the final manuscript.

\section{Funding}

This study was supported by NIH grant T32 GM007618 to VD, NIH grant F30 CA246808 to AC, and the UCSF Physician Scientist Scholar Program, the UCSF Wolfe Meningioma Program Project, and NIH grant K08 CA212279-01 to DRR.

\section{Availability of data and materials}

Details about the methods used for ciliary immunofluorescence, NanoString transcriptional profiling, and molecular and cell biology experiments can be found in Methods. All raw data are available in Supplementary Table S1.

\section{Ethics approval and consent to participate}

This study was approved by the Committee on Human Research of the University of California San Francisco, with a waiver of consent for all patients included in the study (10-01318 and 17-23196).

Consent for publication

Not applicable.

\section{Competing interests}

The authors declare that they have no competing interests.

\section{Author details}

'Department of Radiation Oncology, University of California San Francisco, San Francisco, CA, USA. ${ }^{2}$ Department of Neurological Surgery, University of California San Francisco, San Francisco, CA, USA. ${ }^{3}$ Department of Pathology, University of California San Francisco, San Francisco, CA, USA. ${ }^{4}$ Department of Dermatology, University of California San Francisco, San Francisco, CA, USA. 
Received: 9 June 2020 Accepted: 9 July 2020

Published online: 20 July 2020

\section{References}

1. Boetto J, Apra C, Bielle F, Peyre M, Kalamarides M (2018) Selective vulnerability of the primitive meningeal layer to prenatal Smo activation for skull base meningothelial meningioma formation. Oncogene 122:4. https:// doi.org/10.1038/s41388-018-0328-7

2. Boetto J, Bielle F, Sanson M, Peyre M, Kalamarides M (2017) SMO mutation status defines a distinct and frequent molecular subgroup in olfactory groove meningiomas. Neuro-oncology 19:345-351. https://doi.org/10.1093/ neuonc/now276

3. Brastianos PK, Galanis E, Butowski N, Chan JW, Dunn IF, Goldbrunner R, Herold-Mende C, Ippen FM, Mawrin C, MW MD, Sloan A, Snyder J, Tabatabai G, Tatagiba M, Tonn JC, Wen PY, Aldape K, Nassiri F, Zadeh G, Jenkinson MD, Raleigh DR, International Consortium on Meningiomas (2019) Advances in multidisciplinary therapy for meningiomas. Neuro Oncol 21:i18-i31. https://doi.org/10.1093/neuonc/noy136

4. Brastianos PK, Horowitz PM, Santagata S, Jones RT, McKenna A, Getz G, Ligon KL, Palescandolo E, Van Hummelen P, Ducar MD, Raza A, Sunkavalli A, Macconaill LE, Stemmer-Rachamimov AO, Louis DN, Hahn WC, Dunn IF, Beroukhim R (2013) Genomic sequencing of meningiomas identifies oncogenic SMO and AKT1 mutations. Nat Genet 45:285-289. https://doi. org/10.1038/ng.2526

5. Clark VE, Erson-Omay EZ, Serin A, Yin J, Cotney J, Ozduman K, Avşar T, Li J, Murray PB, Henegariu O, Yilmaz S, Günel JM, Carrión-Grant G, Yilmaz B, Grady C, Tanrikulu B, Bakircioğlu M, Kaymakçalan H, Caglayan AO, Sencar L, Ceyhun E, Atik AF, Bayri Y, Bai H, Kolb LE, Hebert RM, Omay SB, MishraGorur K, Choi M, Overton JD, Holland EC, Mane S, State MW, Bilgüvar K, Baehring JM, Gutin PH, Piepmeier JM, Vortmeyer A, Brennan CW, Pamir MN, Kiliç T, Lifton RP, Noonan JP, Yasuno K, Günel M (2013) Genomic analysis of non-NF2 meningiomas reveals mutations in TRAF7, KLF4, AKT1, and SMO. Science 339:1077-1080. https://doi.org/10.1126/science.1233009

6. Curran T (2018) Reproducibility of academic preclinical translational research: lessons from the development of hedgehog pathway inhibitors to treat cancer. Open Biol 8:180098. https://doi.org/10.1098/rsob.180098

7. Garcia G, Raleigh DR, Reiter JF (2018) How the Ciliary membrane is organized inside-out to communicate outside-in. Curr Biol 28:R421-R434. https://doi.org/10.1016/j.cub.2018.03.010

8. Gilbert LA, Larson MH, Morsut L, Liu Z, Brar GA, Torres SE, Stern-Ginossar N, Brandman O, Whitehead EH, Doudna JA, Lim WA, Weissman JS, Qi LS (2013) CRISPR-mediated modular RNA-guided regulation of transcription in eukaryotes. Cell 154:442-451. https://doi.org/10.1016/j.cell.2013.06.044

9. Ingham PW, Nakano Y, Seger C (2011) Mechanisms and functions of hedgehog signalling across the metazoa. Nat Rev Genet 12:393-406. https://doi.org/10.1038/nrg2984

10. Kline CN, Joseph NM, Grenert JP, van Ziffle J, Talevich E, Onodera C, Aboian M, Cha S, Raleigh DR, Braunstein S, Torkildson J, Samuel D, Bloomer M, Campomanes AGA, Banerjee A, Butowski N, Raffel C, Tihan T, Bollen AW, Phillips JJ, Korn WM, Yeh I, Bastian BC, Gupta N, Mueller S, Perry A, Nicolaides T, Solomon DA. Targeted next-generation sequencing of pediatric neuro-oncology patients improves diagnosis, identifies pathogenic germline mutations, and directs targeted therapy. Neuro Oncol. 2017 May 1; 19(5):699-709. https://doi.org/10.1093/neuonc/now254. Erratum in: Neuro Oncol. 2017 Apr 1;19(4):601. PMID: 28453743; PMCID: PMC5464451.

11. Lang UE, Love NR, Cheung C, McCalmont TH, Kim J (2019) Use of the Ciliation Index to Distinguish Invasive Melanoma From Associated Conventional Melanocytic Nevi. Am J Dermatopathol:1. https://doi.org/10. 1097/DAD.0000000000001459

12. Laurendeau I, Ferrer M, Garrido D, D'Haene N, Ciavarelli P, Basso A, Vidaud M, Bièche I, Salmon I, Szijan I (2010) Gene expression profiling of the hedgehog signaling pathway in human meningiomas. Mol Med 16:262270. https://doi.org/10.2119/molmed.2010.00005

13. Louis DN, Perry A, Reifenberger $G$, von Deimling A, Figarella-Branger D, Cavenee WK, Ohgaki H, Wiestler OD, Kleihues P, Ellison DW (2016) The 2016 World Health Organization classification of tumors of the central nervous system: a summary. Acta Neuropathol 131:803-820. https://doi.org/10.1007/ s00401-016-1545-1

14. Menke JR, Raleigh DR, Gown AM, Thomas S, Perry A, Tihan T (2015) Somatostatin receptor $2 \mathrm{a}$ is a more sensitive diagnostic marker of meningioma than epithelial membrane antigen. Acta Neuropathol 130:441443. https://doi.org/10.1007/s00401-015-1459-3

15. Ostrom QT, Cioffi G, Gittleman H, Patil N, Waite K, Kruchko C, BarnholtzSloan JS (2019) CBTRUS statistical report: primary brain and other central nervous system tumors diagnosed in the United States in 2012-2016. Neuro-oncology 21:v1-v100. https://doi.org/10.1093/neuonc/noz150

16. Patel AJ, Wan YW, Al-Ouran R, Revelli JP, Cardenas MF, Oneissi M, Xi L, Jalali A, Magnotti JF, Muzny DM, Doddapaneni H, Sebastian S, Heck KA, Goodman JC, Gopinath SP, Liu Z, Rao G, Plon SE, Yoshor D, Wheeler DA, Zoghbi HY, Klisch TJ. Molecular profiling predicts meningioma recurrence and reveals loss of DREAM complex repression in aggressive tumors. Proc Natl Acad Sci U S A. 2019 Oct 22;116(43):21715-21726. https://doi.org/10. 1073/pnas.1912858116. Epub 2019 Oct 7.

17. Püttmann $S$, Senner $V$, Braune $S$, Hillmann B, Exeler R, Rickert $\mathrm{CH}$, Paulus W (2005) Establishment of a benign meningioma cell line by hTERT-mediated immortalization. Lab Investig 85:1163-1171. https://doi.org/10.1038/ labinvest.3700307

18. Raleigh DR, Reiter JF (2019) Misactivation of hedgehog signaling causes inherited and sporadic cancers. J Clin Invest 129:465-475. https://doi.org/10. 1172/JCI120850

19. Sahm F, Schrimpf D, Stichel D, Jones DTW, Hielscher T, Schefzyk S, Okonechnikov K, Koelsche C, Reuss DE, Capper D, Sturm D, Wirsching H-G, Berghoff A-S, Baumgarten P, Kratz A, Huang K, Wefers AK, Hovestadt V, Sill M, Ellis HP, Kurian KM, Okuducu AF, Jungk C, Drueschler K, Schick M, Bewerunge-Hudler M, Mawrin C, Seiz-Rosenhagen M, Ketter R, Simon M, Westphal M, Lamszus K, Becker A, Koch A, Schittenhelm J, Rushing EJ, Collins VP, Brehmer S, Chavez L, Platten M, Hänggi D, Unterberg A, Paulus W, Wick W, Pfister SM, Mittelbronn M, Preusser M, Herold-Mende C, Weller M, von Deimling A (2017) DNA methylation-based classification and grading system for meningioma: a multicentre, retrospective analysis. Lancet Oncol. https://doi.org/10.1016/S1470-2045(17)30155-9

20. Sweeney RT, McClary AC, Myers BR, Biscocho J, Neahring L, Kwei KA, Qu K, Gong X, Ng T, Jones CD, Varma S, Odegaard II, Sugiyama T, Koyota S, Rubin BP, Troxell ML, Pelham RJ, Zehnder JL, Beachy PA, Pollack JR, West RB (2014) Identification of recurrent SMO and BRAF mutations in ameloblastomas. Nat Genet 46:722-725. https://doi.org/10.1038/ng.2986

21. Vasudevan HN, Braunstein SE, Phillips JJ, Pekmezci M, Tomlin BA, Wu A, Reis GF, Magill ST, Zhang J, Feng FY, Nicholaides T, Chang SM, Sneed PK, McDermott MW, Berger MS, Perry A, Raleigh DR (2018) Comprehensive molecular profiling identifies FOXM1 as a key transcription factor for meningioma proliferation. Cell Rep 22:3672-3683. https://doi.org/10.1016/j. celrep.2018.03.013

22. Youngblood MW, Duran D, Montejo JD, Li C, Omay SB, Ozduman K, Sheth AH, Zhao AY, Tyrtova E, Miyagishima DF, Fomchenko El, Hong CS, Clark VE, Riche M, Peyre M, Boetto J, Sohrabi S, Koljaka S, Baranoski JF, Knight J, Zhu H, Pamir MN, Avşar T, Kiliç T, Schramm J, Timmer M, Goldbrunner R, Gong Y, Bayri Y, Amankulor N, Hamilton RL, Bilgüvar K, Tikhonova I, Tomak PR, Huttner A, Simon M, Krischek B, Kalamarides M, Erson-Omay EZ, Moliterno J, Günel M (2019) Correlations between genomic subgroup and clinical features in a cohort of more than 3000 meningiomas. J Neurosurg 1:1-10. https://doi.org/10.3171/2019.8.JNS191266

\section{Publisher's Note}

Springer Nature remains neutral with regard to jurisdictional claims in published maps and institutional affiliations.

Ready to submit your research? Choose BMC and benefit from:

- fast, convenient online submission

- thorough peer review by experienced researchers in your field

- rapid publication on acceptance

- support for research data, including large and complex data types

- gold Open Access which fosters wider collaboration and increased citations

- maximum visibility for your research: over $100 \mathrm{M}$ website views per year

At $\mathrm{BMC}$, research is always in progress.

Learn more biomedcentral.com/submission 